\title{
Perlman Syndrome
}

National Cancer Institute

\section{Source}

National Cancer Institute. Perlman Syndrome. NCI Thesaurus. Code C103144.

A rare, autosomal recessive syndrome characterized by the presence of polyhydramnios, neonatal macrosomia, craniofacial abnormalities, nephroblastomatosis, and predisposition to Wilms tumor. The prognosis is poor. 